\title{
CLINES: AN AUXILIARY METHOD IN TAXONOMY
}

\author{
BY \\ Prof. Dr. JULIAN S. HUXLEY \\ Secretary of the London Zoological Society, London \\ With 9 figures
}

While we may hesitate to add to terminology, there are occasions when new terms are a help instead of a burden. I believe this to be so with regard to taxonomic description. The binomial nomenclature is now giving place, in all well-investigated groups, to a trinomial. The third or subspecific name is usually given to geographical groups (subspecies) whether they be geographically isolated or determined only to a zone of intergradation. To the name, a descriptive diagnosis is of course added.

Various difficulties arise. In the first place, where is one to draw the line? Should every geographical group which it is possible to distinguish be raised to subspecific rank? In practice, the arbitrary rule is often adopted (e.g. in ornithology) that this should not be done unless $75 \%$ of the population can be distinguished from the neighbouring subspecies. Secondly, should trinomials be reserved for geographical subspecies? Some authors consider that they should; but others commonly employ them for physiological races, ecological types, paleontological stages, and even for aberrations or the different forms of polymorphic species. It is clear, as Rensch (1934) points out, that too great an extension of the trinomial system defeats its own ends: but how are we to draw the line? Thirdly, while it is known that many organisms vary geographically and ecologically in a graded way, no recognized terminology exists for these gradients. This is unfortunate for several reasons: (a) when gradation exists within a group, the mere conferring of a subspecific or a specific name gives a false impression of the geographical homogeneity of the group. (b) when intergroup gradation exists, mere naming and description of the separate groups not only does nothing to bring out the gradation in their characters, , though this relation of connection may be at least as important as their relation of separation with regard to difference of characters, but it may even serve to disguise it. 
Finally, when an intergroup character-gradient comprises some named (sub. specific) groups and others which are unnamed, this disguises the fact that all the groups are of equal importance in regard to the relation of connection. A name confers a false sense of importance on the named groups (see later, p. 508).

Some authors employ the signs $>$ and $<$ to denote such groups. A.p.x. $\gtrless$ A.p.y. denotes that between the subspecies $\mathbf{x}$ and $\mathbf{y}$ of the species A.p. there is a group which is intermediate both geographically and in its characters. $>$ alone denotes that the intermediate group is more similar to the first-named of the two forms. This, however, although a useful method, does not lay stress on the character which shows gradation, but only on the fact of intermediacy in general.

We may now mention further facts concerning such character-gradients.

Sometimes the gradation does not appear to be related adaptively to gradations in the environment : this aspect of the subject has been recently summarized by Reinig (1938). In other cases the variation is graded in relation to environmental gradients in factors such as temperature and humidity. Rensch (1933, 1936) has summarized the literature and confirmed certain of the rules concerning correlation. Bergmann's rule concerning absolute size in relation to temperature, Allen's rule concerning relative size of exposed parts of the body in relation to temperature, and Gloger's rule or rules concerning different types of pigmentation in relation to temperature and humidity jointly, all in warmblooded animals, embody the best-known cases. However, apparently adaptive geographical gradients are-shown by many other characters as well, such as clutch-size with latitude (in birds), size with salinity in marine organisms, number of fin-vays and vertebrae with salinity, etc., in fishes (Schmidt, 1918), shell-thickness with aridity in landsnails, relative heart-weight with temperature in warm-blooded animals, relative gut-size with temperature in certain types of birds, size and pigmentation with temperature in cold-blooded animals (but with more complex relations than in warm-blooded forms), tongue-length with latitude in bees (Alpatov, I929), temperature-resistance in Drosophila (Timofeeff-Ressovsky, I935). etc. The parallel variation in different geographical regions of numerous Bombus species (Vogt, I909, I9I I) should probably also be included here, though further analysis is desirable. Various American authors have studied the phenomenon intensively in single families or genera, notably Sumner (1929, 1932), in the deermice of the genus Peromyscus. Squirrels are notable for their well-marked correlation of colour with climatic factors (Ingoldby, 1927; Harris, I937). Some of this graded variation (e.g., in relative heart-size) may be merely non-heritable modification; but the majority of these character-gradients undoubtedly are wholly or mainly genetic.

Phenomena of this type are so widespread and so inadequately dealt with by the usual taxonomic practice of merely assigning subspecific or specific names to forms which replace each other geographically, that an addition to 
current terminology seems called for. I have therefore proposed the term cline for a geographical gradient in phenotypic characters (Huxley, 1938). It is not of course intended that specification by means of clines should in any essential way replace the existing method of specification by named, mainly areal, groups : it is supplementary and in some respect complementary.

Theoretically, clines may be of various types:

\section{Discontinuous clines.}

No continuous population exists, but characters vary from one completely geographically isolated group (subspecies or species) to another. Such groups may be the geographical species of an Artenkreis, or the geographical subspecies of a Formenkreis (Rensch, I929, I934). The most obvious cases will concern island or lake forms. The gradient is then biologically in a sense imaginary (though bio-geographically real), viz., the line connecting the mean values of the character at the central points of the areas of distribution of the various separate groups (or, if preferred, the two lines connecting the values at the limits of the areas).

\section{I. i. Discontinuous stepped clines.}

The slope of the general (inter-group) cline is steeper than that of the separate internal clines (see later).

I. I."a. Discontinuous horizontally-stepped clines.

The groups are geographically (though doubtless not genetically) uniform. There is no character-gradient within the separate groups, but the phenotype of each group has a uniform value throughout its area.

I. I. b. Discontinuous obliquely-stepped clines.

As I. I. a., but the internal (intra-group) clines are inclined in the same sense as, though less steeply than, the general (inter-group) cline;-i.e., each group varies geographically within itself, but the amount of change per unit distance is not so great as that between group and group.

From the meagre data available we may conclude that, even when the environmental factor determining the cline varies continuously, the horizontally stepped type of cline (I. I. a.) will be realized when the areas occupied by the separate groups are small, ensuring uniform mixture of genes, but that the obliquely stepped type (I. I. b.) will be realized when the areas are considerable. Since, however, the spread of genes will take place to some extent within each group area, but cannot do so from one group to another, we shall not expect to see realized the case (which would be styled a discontinuous smooth cline) when the slope of compound (inter-group) and internal (intragroup) clines is identical : and a fortiori it would seem theoretically impossible ever to find the slope of an internal exceeding that of the group cline. 
In all clines the slope may vary from point to point. In all discontinuous clines the group areas and therefore the internal clines obviously may overlap geographically as we pass in any particular direction, according to the shapes of the areas.

\section{Continuous clines.}

These will occur when the whole population considered constitutes a single inter-breeding unit. The cline is then a continuous line and a biological as well as a geographical reality.

\section{I. Continuous stepped clines.}

The general cline is divided into comparatively long sections of gentle slope, connected by much shorter sections of steeper slope. The long sections then represent subspecific groups and the short, steeper sections represent the marginal zones of intergradation between groups.

\section{I. a. Continuous horizontally stepped clines.}

The groups (subspecies) are phenotypically uniform and their clines are therefore horizontal. The slope in the short sections is steep but can of course never be vertical.

II. I. b. Continuous obliquely stepped clines.

The internal (subspecific) clines are sloping, but much less steeply than those of the short zones of intergradation.

Thus, the general cline is in the form of a stepped ramp, instead of a staircase as in II. I. a.

II. I. c. Continuous cline of Mixed Slope.

II. I. a. and II. I. b: may be combined, if the central region of each group cline is horizontal, but the edges slightly inclined in the same sense as the general cline.

\section{2. Continuous smooth clines.}

There are no sharp changes in the slope of the general cline, so that the population cannot properly be delimited into subspecific groups. The slope may be uniform throughout, but in most cases will vary from place to place, though never abruptly and never becoming steep.

In many cases, only the subspecific means have been determined, not the gradation within subspecies. In these caces, only compound (inter-group) clines connecting the mean values can be erected. These are biologically unreal, like the similar discontinuous compound clines previously mentioned, and like them must be sharply distinguished from the internal clines, always continuous, which distinguish separate groups (subspecies, intergrading zones, etc.). 
Finally we may note that any type may theoretically be combined with any other or combination of others in every possible way. It is also clear that the slope of a cline may change sign if the related environmental gradient does the same. This occurs, for instance, with the relative size of the wax-gland in bees (Alpatov, 1929). Passing from north to south across Russia the temperature at first rises slowly, then falls rapidly with altitude in the Caucasus: the way-gland's relative size varies inversely with this gradient.

It is to be noted that the mere fact of thinking in terms of clines and visualizing them in the form of graphs immediately suggests certain theoretical conclusions and suggests certain problems for solution. Thus it may safely be said that II. I. b. or II. I. c., with a considerable degree of slope in a considerable region of the separate group areas, are what we may expect in most cases of continuous populations in which distinct subspecies can be distinguished, and what we actually find in the few cases that have been adequately analysed.

The problem then arises as to what maintains the distinctness of the subspecies in such cases : in other words, presents the free spread of genes up and down the general cline, and maintains the steep barriers represented by the zones of intergradation. This is discussed later.

On the other hand, where the environmental factor correlated with the cline remains constant over considerable areas (as may occur with soil-colour), we may expect II. I. a., with no internal gradients, or II. I. c., but with only slightly sloping internal clines, or only over a small marginal region of the group areas.

It is of course not necessarily the case that even approximately regular compound clines should occur within a subspecies, species or group of species ( $\mathrm{Art}$ enkreis). In the first place, in small groups the fixing of accidental variations may occur (see e.g. Sewall Wright, I93I, 1932) and obscure the picture. This appears to have happened in the local groups of various species of land snails, e.g., Partula (Crampton, 1916, 1932). Secondly, the environmental factors, though continuous in their variation, may alter their slope and reverse the sign of their change in an irregular way owing to geographical peculiarities of the region, so as not to produce any broad graded effect. In such cases we shall have an irregular profile of variation instead of an obvious cline. And thirdly, some such environmental factors may not vary continuously at all, but, like soil-colour, change abruptly. This happens, for instance, in the American desert, where the prevailing light sandy colour is interrupted by sporadic outcrops of dark lava, and the coat-colour of the local Peromyscus varies accordingly (Dice and Blossom, 1937). In such cases the profile of variation may be even more irregular, and more abruptly stepped.

The types above enumerated represent the various theoretical possibilities. In practice, very few cases have yet been analysed with sufficient thoroughness for us to be certain of the precise form of the cline. However, Sumner 
(1929; summarized 1932) has provided adequate data in regard to three subspecies of Peromyscus polionotus in Florida, viz., (I) P.p. leucocephalus from an isolated island reef of white sand. (2) P.p. albifrons from the coastal strip of the mainland opposite, the width of the strip being almost 40 miles. A narrow zone by the coast has white sand, as on the habitat of P.p. leucocephalus; then follows a zone of rather pale sandy soil; but the most inland part of the population is on dark soil like that in the area of the third form. (3) P.p. polionotus is found still further inland, and throughout its range exists on very dark soil. The chief difference between the three forms lies in their colouration, the island form being almost white, the coastal form pale, the inland form dark. The difference in colour was quantitatively estimated in various ways, e: g., (I) by planimetric estimation of the area of the coat where hairs are pigmented in their entirety; $(2)$ by the colorimetric estimation of the amount of red in the pelage, increase of red being a measure of increasing paleness; and (3) the length of the pigmented dorsal tail-stripe (expressed as a percentage of total tail-length). Data were obtained from large collections at points along a line running inland from the coast.

These data showed ( $I$ ) that the island form was geographically uniform, though presumably genetically variable, throughout; (2) that the coastal form showed a marked cline of increasing pigmentation; (3) that the inland form, while practically constant in the most inland parts of its range, showed a slight cline of increasing pigmentation in its most coastal sector; (4) that at about 40 miles from the coast there is a zone of intergradation only a few miles wide, in which the cline rises very steeply; (5) in addition, the coefficient of variability shows a marked rise in the centre of the zone of intergradation.

The facts are shown graphically in Fig. I. This is modified from Sumner, 1932, Figure 17, with the addition of points for the island form. Sumner, although giving the standard deviation, does not plot the coefficients of variability. This I have done in Figure I.

The relations of the pigmentation cline to the environmental factors are interesting. The environmental factor in question appears to be soil-colour, (as is clearly established for certain subspecies of Peromyscus inhabiting lava outcrops in the American desert (Dice and Blossom, 1937), which are very dark, in marked contrast to the surrounding light forms on sand, in spite of conditions of temperature and humidity being practically identical ${ }^{1}$ )). However, the zone of intergradation between coastal and inland subspecies does not occur at the spot where the soil-colour changes, but somewhat further inland.

Consideration of the cline for the whole population leads to numerous interesting conclusions; ( $I$ ) where, as in the island form, a group is com-

I) In other cases (Sumner 1932 p. $71-72$ ) the mice on the lava are of the same pale colour as those on the surrounding sand. This would indicate (I) that selection for cryptic resemblance is not very intense; and/or (2) that colonization of the lava has been recent and that mutations are infrequent. 
pletely isolated on white soil, selection has achieved a striking approximation of coat-colour to soil-colour. The same is true of the inland section of the inland form; (2) where a group exists on white sand, but is not isolated, as with the beach inhabitants of P.p. albifroms, the degree of cryptic resemblance achieved is by no means so close. This must be due to the infiltration of genes for dark pigmentation by intercrossing with darker forms from further inland,

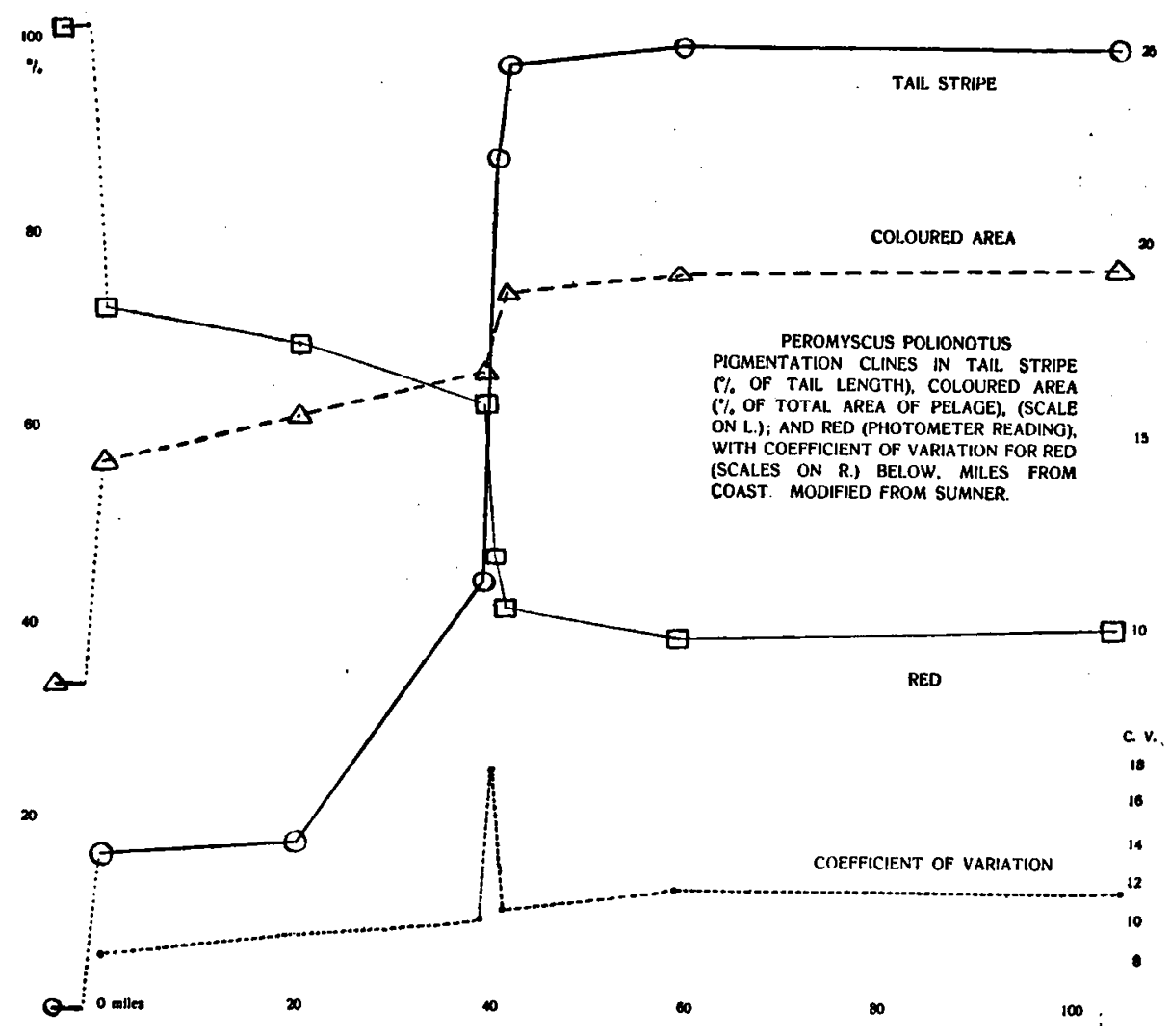

Fig. I. Internal clines for pigmentation and variability in Yeromyscus polionotus (modified from Sumner, 1929).

both of the same and of the P.p. polionotus subspecies, and shows that the selection-pressure for resemblance to background cannot be very high 1); (3) the fact that the pale coastal form extends inland for a considerable distance beyond the pale soils must, as Sumner concludes, mean that the coastal form, after being differentiated on the sandy (and white) soils of the coastal strip, has increased in numbers and extended its range inland on to dark soil. This

1) This is also shown by an observation of Sumner's (1932, p. 70) on a colony of albifrons almost isolated on a reef of white sand, which showed no marked lightening of colour. This he ascribes to the recent colonization of the area. 
would of itself lead to some adaptive darkenning of the most inland section of the population, and would contribute to the incomplete lightening of the extreme coastal (white sand) section. (4) The coastal and inland forms, though intergrading, can rightly be classified as separate subspecies, since their clines are connected by a very steep section of the general cline, and further the increased variability in this region demonstrates that two genetically distinct populations are here undergoing crossing.

A similar cline, this time apparently correlated with gradients in rainfall, is seen in P. maniculatus from California (Sumner, 1932, p. $5^{8}$ and fig. 14). Here again, though the general slope of the cline is continued throughout the whole area, the demarcation between the subspecies P.m. gambelii and P.m. rubidus is marked by a zone of rapid change of slope.

These zones of intergradation and rapid phenotypic change are well-known features in species with continuous range but divided into recognizably distinct groups, and can be taken as evidence that the groups merit subspecific rank. What is not yet ascertained except for a very few examples is whether the subspecies in such cases are geographically uniform, or show an internal cline of their own of the same type as, though less steep than, the inter-group cline. On theoretical grounds we may assume that where an inter-group cline exists and is correlated with graded environmental features such as temperature or humidity, the separate subspecies will themselves show geographically graded variation, with clines whose slope is determined jointly by the intensity of selection, by the amount of infiltration of genes, by inter-crossing with neighbouring subspecies, and by the amount of range-change which has occurred in the subspecies. Where, on the other hand, the subspecific characters are correlated with local factors which may remain constant over a considerable area, such as soil-colour, we may expect to find a horizontally stepped-general cline: or possibly the central regions of each subspecies will be geographically uniform, with a marginal slightly sloping cline due to infiltration of alien genes.

In passing, it appears clear from Sumner's results and those of other workers that regular clines in animals are not to any appreciable degree mere modifications, due to the direct action of environmental factors, but have a genetic basis. In most cases their explanation appears to be selective. However, many graded characters must be what Darwin called "correlated characters," the outward and visible (but biologically unimportant) signs of deep-seated and important (but not immediately conspicuous) physiological characters. For such characters we may speak of selection as being indirect. With pigmentation, selection may in some cases be direct, in relation to cryptic resemblance, as in P.p. leucocephalus; but in many other cases indirect, not in relation to soil-colour but to temperature and to humidity. That deep-seated, physiological characters of a type which would be expected to influence pigmentation, proportion of parts, etc., may characterize geographical groups, is shown by the work of Yocum and Huestis (1928), who find 
marked genetic differences in the thyroids of two subspecies of Peromyscus from an arid and a humid region respectively.

Matters are more complex in plants, owing to the great degree of direct modifiability (plasticity) shown by many species. We may thus find nongenetic clines in plant species and shall doubtless do so in those types of lower animals which are plastic, such as corals or sponges. However, clines such as those seen running through successive ecological zones of the habitat of such plant forms as Plantago maritima seem to be genetic and due to selection (Gregor, I938). Such clines are short and may be called ecoclines in contradistinction to the more extensive clines, (geoclines) extending over long distances, previously considered. Geoclines are more prevalent in animals but it is probable that many ecological types of land-snails (related to shade, moisturè, open exposures, high, altitude, calcareous soil, etc.) can be subsumed under the head of ecoclines (Rensch, 1934).

The adoptation of specification by clines for all ecologically-graded variation would relieve the literature of a vast number of trinomials which are not only useless but hinder the proper main use of trinomials to denote groups which have a relatively independent existence as separate groups in nature.

Mr. Melville of Kew informs me that in certain arrays of forms apparently produced by hybridization, e.g. in elms (Ulmus), the various types, while showing no geographical gradation, are susceptible of arrangement in a graded series, which indicates the end-forms between which crossing is presumed to have occured. Such artificial gradations may be called taxoclines. In paleontology definite recurrent trends are often found-e.g. to the incurved forms of oyster known as Gryphaea. Some authors suggest using trinomials for the successive stages of such a trend. It might be more convenient, however, to obviate this by specifying the trends, perhaps under the need of chronoclines.

An interesting case is that of the small copper butterfly (Heodes phloeas). FORD (I924) finds various distinct clines in certain regions, while in North America the species is practically uniform over large areas. This FoRD ascribes to the recent colonisation of America by the species, so that there has been insufficient time for geographical differentiation to have been achieved, Chapman and Griscom (1924) suggest a similar explanation for the lack of marked pigmentation-clines in the South American house-wren, Troglodytes musculus. Here, however distinct clines towards increased size with altitude are found, presumably indicating that selection for greater size with lower temperature is more intense than for the qualities determining pigmentation in relation to temperature and humidity.

The value of specification and description with reference to clines, in addition to the current practice of specification and description with reference to named areal groups, is shown by such cases as that of the cole tit (Parus ater) in western Europe. These subspecies are distinguished in this region: P.a. ater from most of Continental Europe; P.a. britannicus, from Britain; 
and P. a. hibernicus from Ireland, in Witherby's Practical Handbook (1920I924) (see Witherby, 1938, for the latest revision).

The description of these three subspecies (there are many others in other regions) occupies 98 lines of print. From this mass of detail we may if we like select the following points of difference between the forms, using P.a. britannicus as the standard of reference.

(I) Adult.

Nuchal patch.

Cheeks and ear-coverts. Purer White

Rump.

Mantle, scapulars and back.

Upper tail-coverts.

Black of throat.

Fringes of tail and wingfeathers and wing-co-

verts.

Tips of greater and median coverts.

Central underparts.

Sides, flanks and under tail-coverts.

Measurements.

\section{(2) Juvenile}

Nuchal patch.

Mantle, scapulars and back.

Cheeks and ear-coverts. Paler yellow, sometimes almost white.

Sooty brown of throat. More extensive.

Under-parts.

Not so olive.

More grey, sometimes washed greenish.

Greyer.

More extensive if series are taken.

Greyer, not so greenish.

Usually purer white.

Duller buff. tarsus which is smaller. ler.

Usually white.

Greenish-grey, not

brownish-olive.

Slightly larger, except Perhaps a shade smal-

Pale yellow or yellowish white; not pure white.

Yellower buff.

More strongly washed olive-buff.

Tinged yellow.

Yellow or yellowish white. 
As a matter of fact these differences can all be subsumed under the head of two, or perhaps, three clines running from east to west.

(I) A marked cline towards increase of yellow (lipochrome) pigmentation; (2) a very slight cline towards decrease in size; (3) a possible very slight cline towards decrease of melanin pigmentation (as shown by the extent of black on the throat, notably in juveniles). Here we need only concern ourselves with the first of these. Increase of lipochrome tinges white parts with yellow and makes parts with moderate melanin pigmentation olive-buff instead of slategrey. A mere qualitative specification of this cline will save the systematist or other biologist anxious to discover regularities in the welter of taxonomic

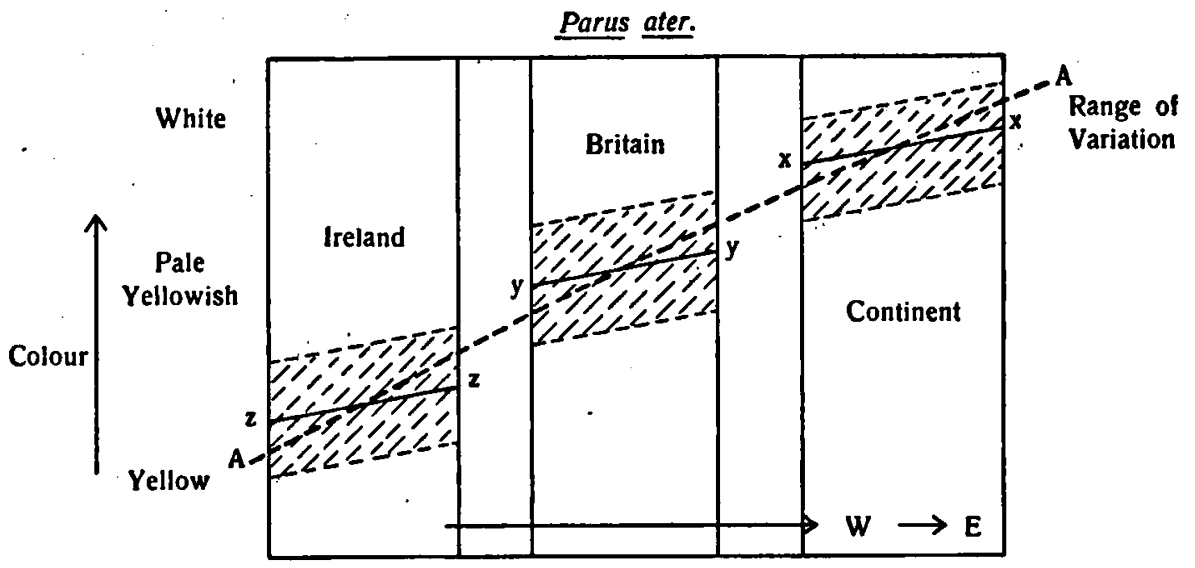

Fig. 2. Diagram of probable pigmentation clines in Parus ater in W. Europe : intergroup cline (A-A) for increasing yellow (lipochrome) pigmentation from E. to W.; internal clines of the same character but of lesser slope $(x-x, y-y, z-z)$. The range of variation of the Irish and British froms is known to overlap in E. Ireland and W. Britain. There is as yet no evidence for any overlap between $E$. Britain and W. continental forms, and there may prove to be no such overlap, and no internal cline within the continental forms.

detail, a great deal of time and trouble. Analysis along these lines could readily be taken a stage further by the use of colorimetric determination with a tint photometer, as employed by Sumner for his mice, when we should be able to construct a graph.

By thinking in terms of clines, interesting conclusions can already be drawn from the data as at present set forth. For instance, Witherby (op. cit.) mentions with regard to the Irish subspecies that "occasional specimens, especially from north-east Ireland, even in winter are indistinguishable from P.a. britannicus, while others have only a faint tinge of yellow on ear-coverts or belly." And a note in the 1938 Edition (p. 258 ) informs us that occasional specimens of the British subspecies from western Britain (Wales) "show, varying markedly in degree, some characteristies of the Irish form". The same foot-note, 
states that some specimens of the Irish subspecies, "especially from Co. Down are not separable from P.a. britannicus". This at once implies the interesting fact that the cline for yellow, though geographically interrupted by the Irish Channel, is still operative within the two separate groups concerned, although it is clear, as was suggested on p. 493 would be the case on theoretical grounds, that the internal slopes are much less steep than that of the compound (intergroup) cline. The resultant condition is diagrammatically indicated in Fig. 2.

We see here that specification by names for areal groups automatically suggests both an undue degree of biological reality for such groups as opposed to others which remain unnamed, and also a degree of geographical uniformity

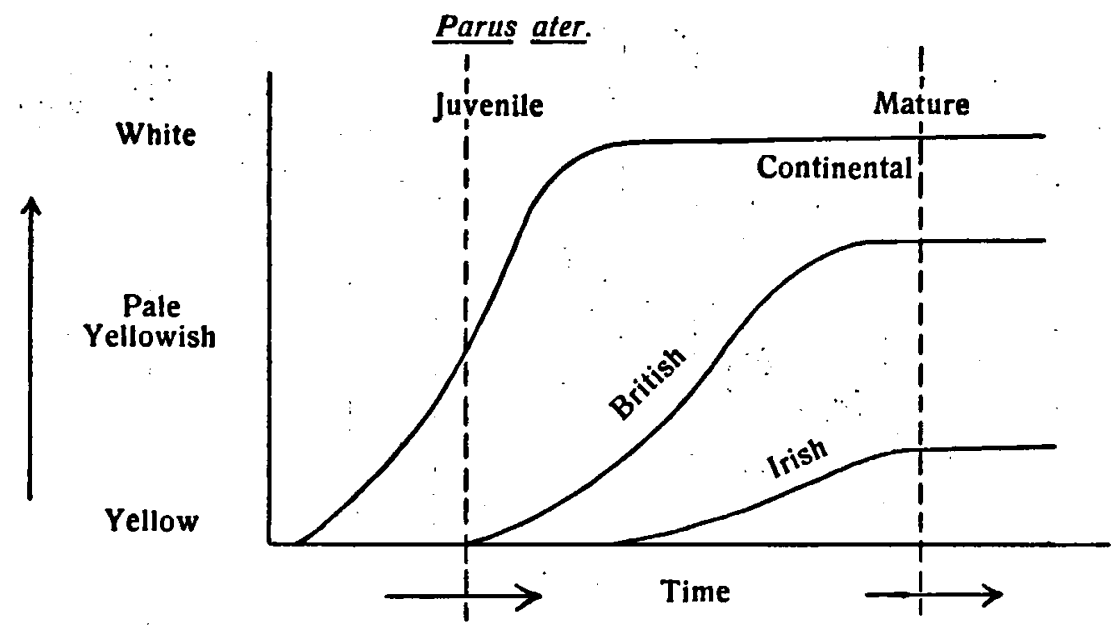

Fig. 3. Diagram of the ontogenetic basis for the pigmentation cline in Parus ater. The more intense the action of the rate-genes affecting decrease of lipochrome pigmentation with time, the earlier their onset, and the greater their final effect. Only in the continental form is the gene's action intense enough to be manifested before the juvenile stage.

within such groups which is not in accordance with the facts. Specification by means of clines automatically corrects these defects, and draws attention to inter-group regularities and to facts which cannot readily be fitted into a scheme of areal groups.

The relation of juvenile to adult plumage in the three forms suggests further methods of specification. Juveniles are always yellower than adults; but whereas British and Irish juveniles are indistinguishable, those of the Continental form are much less yellow. If these facts seem puzzling at first sight, they are not so to those who have followed recent work on the relation between genes and their expression in phenotypic characters. It has been shown that in many cases, degree of phenotypic expression is controlled by rate-genes, which have the following properties: (I) they control the rate of a process; (2) the 
intensity of their action in this respect is usually correlated with early onset of visible action and level of final equilibrium-position attained by the character (FORD and HuXLEY, 1929). The facts in this case can at once be fitted into such a scheme, applicable to the speed of a process inhibiting the amount of yellow pigment produced (Fig. 3).

Such graded changes of phenotypic characters during development may perhaps be styled ontoclines.

Owing to the fact that moults only occur at definite times, it is impossible in birds to study the actual shape of such curves by observation, unless experiment is called in, and feathers are plucked and allowed to regenerate at intervals between moults. A precisely similar case, on which more continuous curves could be

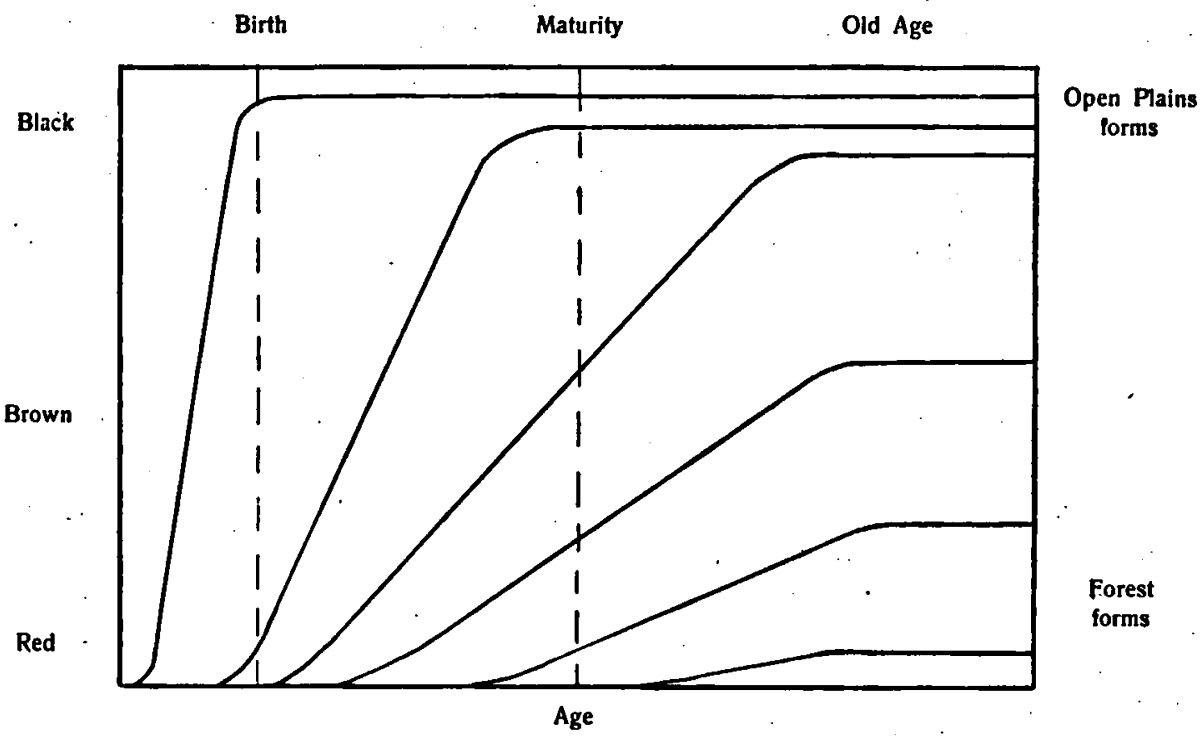

Fig. 4. Diagram of the ontogenetic basis for the pigmentation-cline in African buffaloes. The rate-genes involved affect the change from red to black pigment.

obtained, is that of the African buffaloes (CHRISTY, 1929), in which a cline from pale red forest adults to black plains adults is found, and has its developmental basis in an increase of the slope of the ontocline from red towards black colour (fig. 4). In any case I feel sure that analysis along such lines, now that the mode of action of rate-genes has been in principle elucidated by GoldsChMIDT (1938) and FoRD and HUXLEY (op. cit.), will prove of great assistance in taxonomic work. (See also HuXLEY, 1932, Chapter 7, for the bearings of similar work concerning relative growth on tanonomy and evolution; also VoGT and VoGT (1935 and 1936) for others cases where phenotypic trends are consequential upon changes in ontogenetic processes). To pursue the subject further, however, would necessitate separate treatment. 
It is noteworthy that clines for different characters need not coincide. Thus Swarth 1920) in fox-sparrows Miller (I93I) in shrikes and MiKer and MCCABE (1935) in Lincoln sparrows found clines for different characters running in different directions. Again, different clines running in the same direction may behave differently. The north to south cline in increasing size of the tongue in honey-bees (Alpatov, 1929) has already been referred to, and the phenograde for relative leg-length behaves in the same way. But those for abdomen-colour and for rlative size of wax-gland, while behaving similarly in the region of the Russian plain, are reversed in sign on reaching the Caucasus, and thus appear to be related to temperature as this decreases with altitude.

LinSDALE (1938) finds inter-subspecific clines in numerous birds in Nevada. General size and amount of white in plumage diminish from N.E. to S.W., and wings and tail become longer; plumage becomes paler and distinctly greyer (in adaptation to background coloration) to the east, and sometimes lighter and more intense towards the Colorado River in the south.

This is another reason for thinking it desirable to introduce specification by clines as an additional method of taxonomic description. It is clear that the definition of two or three well-defined clines which run in different directions across the range of a species will give in handy form a great deal of important information which could only be extracted from subspecific descriptions by the expenditure of a great deal of time and labour. In addition, when marked clines cover large areas without being abruptly stepped at intervals, to allot subspecific names to a number of forms gives a false impression, while the inclusion of all types under one areal name neglects the facts of difference. Mr. Moreau of Amani, Tanganyika, informs me that this condition appears to hold for various East African birds.

A special type of cline of peculiar interest is that in the proportion of the various forms of dimorphic or polymorphic species: this we may call a cline in dimorph (or polymorph) ratio.

The classical cases are the Arctic Fox (Alopex lagopus) and the American Red Fox (Vulpes fulva) (Elton 1930, p. 80) and the Common Guillemot (Uria aalge). In the foxes the percentage of the different colour-phases changes geographically, but MR. ELTON tells me that the relations are complex and need detailed analysis. In addition, the inclination of the cline would appear in some cases to change in relation to the periodic fluctuation in numbers to which the species is markedly subject. This latter point, if established, would go to prove the correctness of R. A. FISHER's view (I930) on the selective balance underlying dimorphism, which would respond differentially to the different types of selection exerted at different points of the cycle.

In the guillemot a 'ringed', 'spectacled', or 'bridled' form exists, which possesses a white line running forward to and encircling the eye. This is usually described as a rare variety or aberration, but while this is so in Southern and 
Western England, where spectacled birds are always rare, in Iceland the variety is two or even three times more abundant than the 'type' 1).

Great gaps exist in our knowledge, but it seems clear that there exists a southern region where the bridled form never reaches $\mathrm{I} \%$ a northern region (figures available from N. Cape, Iceland and Bear Island) where it is over $50 \%$, and an intermediate region (Faeroes, north and east Scotland and the Isles, Northumberland) in which a dimorph ratio cline exists, though apparently with some irregularities. A further interesting point is that two or more subspecies can be distinguished in the area, and that the limit of the southern subspecies. (U. a. albionis) appears to coincide more or less with the sharp slope of the ratio-cline. However, further work may show that the cline-slope will here reveal a broad zone of intergradation. In any case, much detailed observation, especially in Scandinavia, Greenland and eastern U.S.A., is needed before any adequate interpretation of the facts can be given. The preliminary results of the investigation of this subject, undertaken for the British Trust for Ornithology, have been published by Southern (1939).

Similar gradients may exist in highly polymorphic species in which sharply distinct forms are not distinguishable. Thus, Mr. E. B. Ford informs me that the moth Xylophasia monoglypha ranges continously from almost black to quite light in colour; but in Britain at least the proportion of darker forms decreases regularly from north to south.

DobZhansky (1933) has found polymorph ratio clines affecting the geographic fresquency of the various patterns of certain lady-beetles. In addition, this is combined with simple pigmentation-clines affecting the development of single spots within the patterns of various of the polymorphic forms.

A beautiful case of a dimorph ratio cline has recently been reported by Pearson (1938). The Brush Opossum, Trichosurus vulpecula exists in Tasmania as a distinct subspecies $T$. v. fuliginosus, while $T$. v. vulpecula occurs on the neighbouring mainland. On the mainland the type is grey and melanic variants are very rare. In Tasmania, however, black forms are common. Pearson has succeeded in mapping the percentages of black and grey in a series of over 58,000 Tasmanian pelts. His results are shown in fig. 5. In a small area on the N.W. all are black: the percentage of black decreases eastward, until in two areas they are under $25 \%$ (in some localities under Io \%). In two islands off the W. and $E$. ends of the $N$. coast, all are grey: one of these islands must have formed part of the land-bridge by which the land fauna entered Tasmania from the mainland, but the other can not have done so. These facts would indicate that at some period subsequent to the separation of Tasmania from the mainland, a black mutant appeared in the N.W., and,

1) I am referring to the Old World. Apparently the bridled type does not occur at all in the subspecies from the North Pacific, and in the eastern American bird all that is known is that the hidled variety does occur in proportion of about $15 \%$ in the St. Lawrence region. 
being favoured by selection, has spread gradually over the island. The map (fig. 5) indicates that it has spread faster along the coast than through the interior. The narrow base of the Forestier-Tasman's peninsula on the S.E. has apparently hindered the spread of the black form into this region ${ }^{1}$ ).

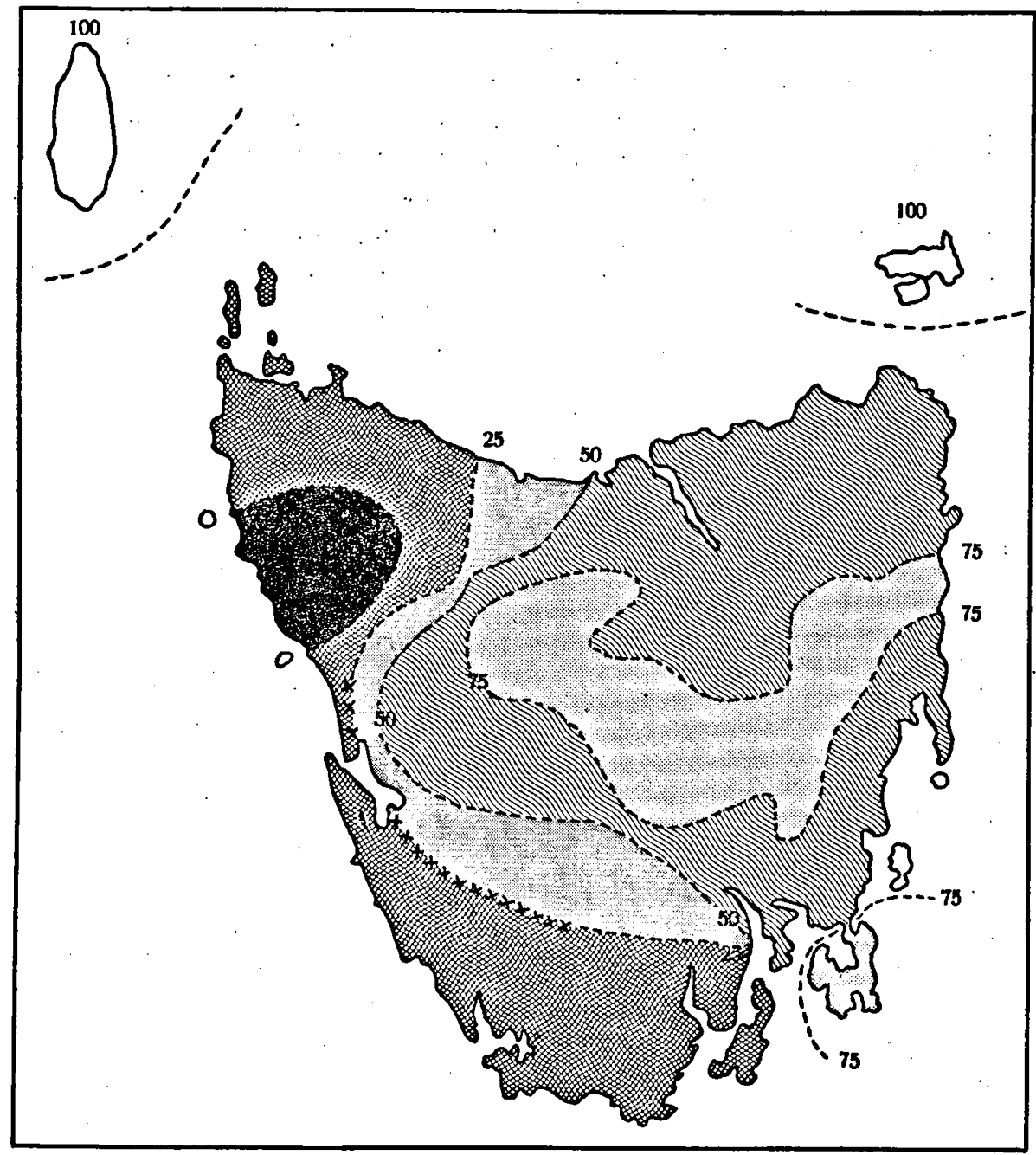

Fig. 5. Dimorph ratio clines in Trichosurus vulpecula. The distribution of the grey and black varieties in Tasmania and neighbouring islands is shown. $x \times x$ extrapolation (no records available in this area). Modified from Pearson 1938.

Zimmerman has studied a somewhat similar case concerning the fieldvole Microtus a. arvalis in central Europe. The character here is the so-called

1) Pearson himself adopts a somewhat different hypothesis, but one which in my opinion is not warranted by the facts. 
simplex type of teeth, characterized by the absence of the $4^{\text {th }}$ internal loop of enamel on the $4^{\text {th }}$ upper molar. 4200 skulls were investigated. The simplex character occurs in over $90 \%$ of the specimens in Schleswig, and the percentage decreases in roughly concentric gradations from this area until it is present in under $5 \%$. From the map it appears that the character (as with the Opossum) must have spread from its area of highest incidence: mountains and rivers have acted as complete or partial barriers to its spread. For further examples (Epilachna, Cricetus) see TimofeefF-Ressovsky, 1939.

A peculiar type of cline, hitherto unique, is that discovered by FischerPiette (1935) in Limpets (Patella). In these, areas exist where distinct non-

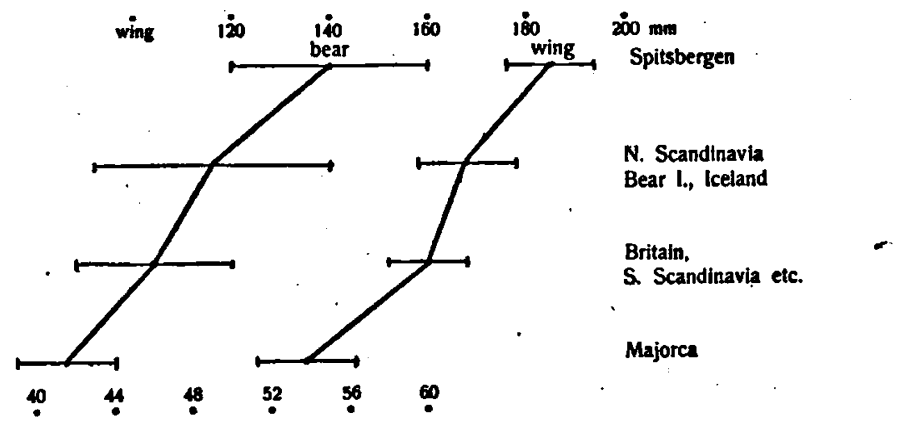

Fig. 6. Inter-group size clines for beak-length and winglength in the puffin (Fratercula arctica); from combined data of Witherby and Hartert. The horizontal lines respresent the size-ranges of the various subspecies, and the clines connect the mid-points of the ranges (means are not available). The rate of change is $1 \%$ per $1.1^{\circ}-$ I. $2^{\circ} \mathrm{N}$. lat.

interbreeding types exist, and others where similar types exist as part of a very variable single interbreeding population. Clines exist in respect of the degree of distinctness of the types (absence of interbreeding between them).

In general, Reinig criticizes Rensch's views, and wholly rejects the idea of clines adaptively correlated with environmental gradients. Instead, he adopts the view that they are invariably associated with migration, factors being according to him dropped out of the gene-complex of the species during the process. One result is stated to be that size decreases with distance from the centre of distribution from which migration has proceeded. The migrations concerned are according to him almost invariably connected with the marked changes of climate since the last warm interglacial period, and mainly with postglacial changes.

Such a concentric diminution of size round centres of postglacial distribution does appear to hold for certain mammals, e.g. the American beaver, Fiber zibethicus, (Reinig, fig. 22, p. 100) and the European red deer, Cervus elaphus, 
(ibid p. $\cdot 102$ ), in neither of which can correspondence with the usual temperature rules be found.

When, however, he attemps to explain all size-clines in this way, he would appear to be too sweeping. I have combined the data from Witherby's Handbook of British Birds and Hartert's Birds of the Palearctic for one or two cases. The results are shown in fig. $6-8$. The puffin (Fratercula arctica) ranges from the Balearics to Spitsbergen in 4 subspecies. Contrary to my expectation, the $\mathrm{S}-\mathrm{N}$ cline for wing-length shows no steeper a slope than that

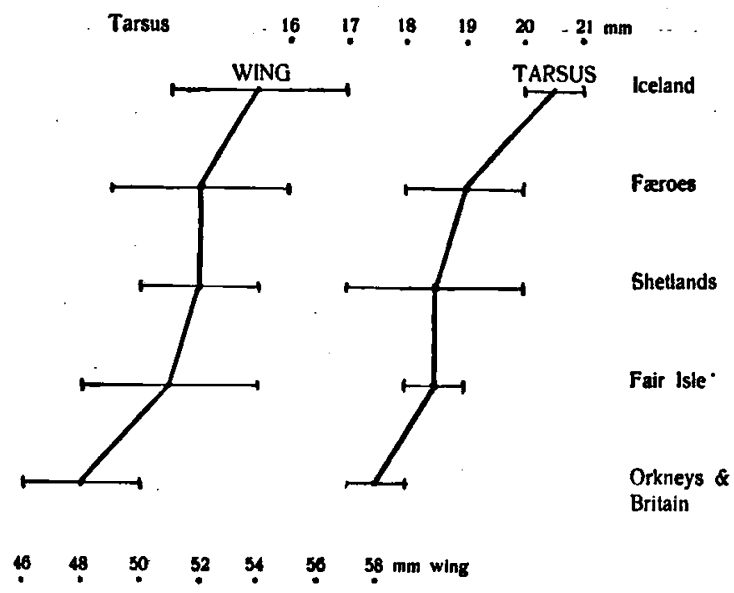

Fig. 7. Inter-group size-clines for wing-length and tarsus-length in the wren (Troglodytes troglodytes). Data and treatment as in fig. 6. Rate of change I $\%$ per $0.5^{\circ}-0.66^{\circ} \mathrm{N}$. lat.

for beak-length, an increase of I $\%$ for I.I ${ }^{\circ}$ to $1.2^{\circ} \mathrm{N}$. latitude (fig. 6). The common wren (Troglodytes troglodytes) has subspecies in the Shetlands, the Faeroes and Iceland, and in addition the population in Fair Isle ${ }^{1}$ ) is intermediate both phenotypically (in size and also in pigmentation) and geographically between the Shetland form and the typical subspecies, which reaches the Orkneys from the British mainland (fig. 7).

1) Incidentally the case of the Fair Isle wrens provides another example of the usefulness of specification by clines. Their differences are so slight that not even the most inveterate "splitter" has ventured to name them as a distinct subspecies; but the fact that they fall on a $\mathrm{S}-\mathrm{N}$ cline is obviously of biological interest and subsumes the taxonomic facts concerning them together with these concerning the neighouring subspecies. Mr. Fraser Darling tells me that there appears to exist a similar cline from the Scottish mainland wrens through those of the Summer Isles to the Outer Hebrides.

Since writing the above, my attention has been drawn to the analysis by Salomonsen (I933) of wrens from the same area, but based on different specimens. He arrives at very similar conclusions, finding that wing-size varies in direct proportion to distance from the British mainland. 
Here the distance covered by the cline is far less, but the slope is actually steeper - I $\%$ of change in tarsus-length and in wing-length per $0.5^{\circ}-0.66^{\circ}$ $\mathrm{N}$. lat. In passing, the wrens provide a puzzle, in that, while this marked cline exists to the nonthwards of Britain, there is great uniformity in the wren population of Britain and the adjacent parts of western Europe, all of which is referred to a single subspecies. It is possible, of course that intensive analysis would reveal a gentle $\mathrm{S}-\mathrm{N}$ internal cline within this group also, as well as the compound inter-group cline to the $\mathrm{N}$.

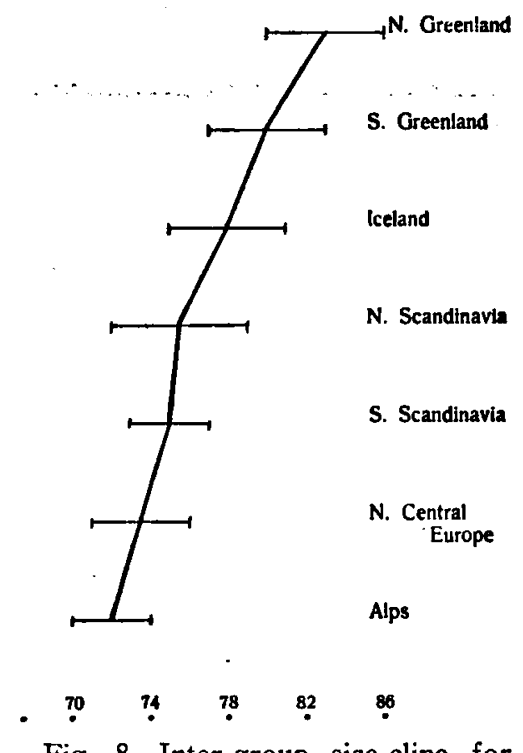

Fig. 8. Inter-group size-cline for wing-length in male redpolls (Carduelis flammea [C. linaria]). From data in Reinig 1938. Treatment as in fig. 6 and 7 . Rate of change $1 \%$ per $2^{\circ} \mathrm{N}$. lat.

Reing himself cites the case of the redpolls; Carduelis flammea in the broad sense. These range from the Alps to N. Greenland, and over this range shows an increase of $1 \%$ in winglength per $2^{\circ} \mathrm{N}$. lat. (An exceptional position is taken by the British population, which is even smaller in size than that from the Alps) (fig. 8).

Reinig's theoretical genetic explanation is also hard to follow. For the present, we may say that some clines appear to be adaptively correlated, either directly or indirectly, with environmental factors; others are due to the localized appearance and subsequent spread of a mutation posessing selective advantage; and still others to be correlated with migration, though the precise mechanism of this correlation is at present uncertain. However, the fact that 
clines may be of different types and due to different evolutionary causes in no way detracts from their utility as a means of taxonomic specification, any more than the undoubted fact that non-interbreeding groups may arise in numerous ways detracts from the utility of the concept of species.

One general point remains to be discussed, namely the fact we have referred to before, of the widespread existence of stepped continuous clines - in other words of interbreeding populations which are biologically continuous over large areas, but are divisible into distinct subspecies connected by narrow zones of intergradation. It is at first sight difficult to understand how these zones of intergradation are maintained. They represent pantial breaks in the biological continuum, definite barriers to the free flow of genes from one area of the group's range to another. One might reasonably expect that these steps would be progressively broadened and flattened until a cline of uniform slope resulted. In point of fact, the sharpness and narrowness of these zones is one of their general characteristics: that between the two mainland species of Peromyscus polionotus, mentioned earlier, was only 3 miles wide.

Is is of course possible that such zones may be secondary zones of meeting, consequent upon migration after the two groups have differentiated in isolation. Some cases of this are known, the most spectacular being that of the Hoodie and Carrion Crows (Corvus cornix and Corvus corone), which intergrade over a zone some 2000 miles long, but only 50-100 miles wide (MEISE 1928). There seems no question that this is due to isolation of three groups during the glacial period in the western palearctic, the central one having developed into the Hoodie type, the western and eastern ones remaining full black, the process followed by complex postglacial migration. More often however, such migrations, when they can be legitimately deduced, seem to result in less narrow and less extended areas of intergradation. In any event, the very large number of cases in which geographical replacement of forms occurs over the whole of a considerable area, but with narrow intergrading zones between the forms, can assuredly not be explained on the hypothesis of rejoining after isolated differentiation (although this appears to be the view adopted by an authoritiy such as ÖKLAND, 1937).

One notable contribution has been made to the problem by TimoferfFREssovsKY (1932) in his genetic analysis of geographical variation in pattern in the lady-beetles, Epilachna chrysomela. He found that the various patterns depended on a considerable number of genes, and that the gene-combinations giving rise to the most frequent patterns, characteristic of large areas, hadselective advantages in viability and vigour over other gene-combinations.

If so, then we may reasonably assume (I) that there is a local selective value attaching to certain gene-combinations, each of the favourable combinations being adapted directly or more possibly indirectly to certain regional peculiarities of the environment; (2) that owing to their greater viability, these gene-combinations came to possess a greater geographical range than would 
otherwise be expected, the intermediate types of pattern only ocurring as a result of intercrossing at the boundary of the two favoured forms, and being prevented from spreading by selection. (See also TimofEefF-RessovsKy, 1939).

Prof. R. A. FISHER in conversation has suggested that we should expect such conditions to be generalized wherever a population extends over a considerable area comprising regions that were climatically (or in other ways affecting the species) distinct. Then seleotion will operate to adept the population regionally, but whenever what one may call the biological tension between two regions is sufficient, a partial biological discontinuity will result, in the same way that certain fabrics show incipient tears under stress. The precise modus operandi would be as follows. Whenever two relatively large and uniform areas were separated by regions of relatively rapid environmental change, the effect of selection would be to produce two main types of gene-complex, each stabilized by its own set of modifiers giving maximum harmony and viability. So long as the population is continuous, these will interbreed where they meet. But the recombinations between them being ex hypothesi less well adapted and harmonious than either of the two main complexes, will remain restricted to a narrow zone and will not spread progressively through the population.

A similar effect may be expected when a partial discontinuity is broughi about by extrinsic causes (partial isolation) - e.g. where an area of relatively sparse population is interposed between two areas of greater density, which are further distinguished by some degree of environmental difference. The obstacle to free gene-flow will render it easier for selection to build up distinctive gene-complexes in the two dense areas, and their greater harmony and viability, once established, will extend their ranges so as decrease the intermediate area to a narrow zone.

Of course migration may operate to complicate the picture. It is important to note that even when one subspecies increases its area at the expense of another continuous one, the intergrading zone would on these principles continue narrow. Sumner. (1932) has suggested that such range-changes are probably frequent. He compares continuous subspecific populations to a number of bladders under different degrees of inflation, the pressure in the bladder representing the population-pressure within the subspecies. Changes in relative population-pressure in adjacent species will produce an expansion of range of one, a diminution in the other. In the bladder simile the zone of demarcation is given by the skin of the bladder itself, but Sumner does not explain why any biological equivalent should remain so sharply demarcated. The principle of local stabilized gene-complexes immediately provides an answer. The narrow zone of relatively unfavorable gene-combinations is maintained at its approximate original width in spite of being displaced by the changing population-pressures.

Dr. C. D. Darlington in conversation has suggested to me that the 
widespread existence of large chromosomal inversions or translocations in natural populations would favour the development of partial discontinuity, since the partial gene-complex within each such chromosomal region would be stabilized at maximum harmony and prevented from forming recombinations with its homologues, thus providing ready-made a larger basis for the existence of regionally stabilized differentiated complexes than would be possible if free recombination were universal.

The same principle of stabilized gene-complexes, by the way, will explain the otherwise puzzling fact of the narrowness of the zone of interbreeding in the crows and other cases of meeting after isolated differentiation, in spite of the lapse of millennia. Here again it is difficult to imagine that Hoodie and

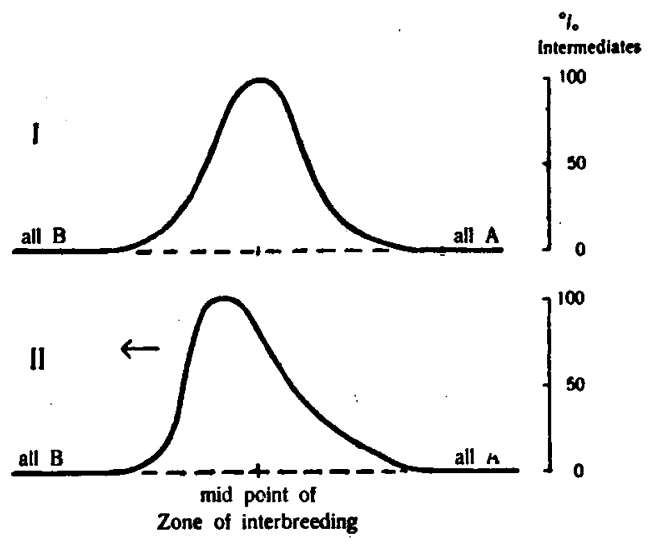

Fig. 9. Possible types of zones of interbreeding between two intergrading forms. I. When the boundary between the forms is stationary; II. When form $A$ is expanding its area at the expense of form $B$.

Carrion Crows are in perfect equilibrium: but even if one is increasing its area at the expense of the other, the zone of mixture will remain narrow.

Various points of theoretical interest arise in relation to such geographical shifts of narrow recombinational zones. It might for instance be suggested that whereas when no shift was occuring the distribution of intermediate characters across the zone would be symmetrical, a shift would render it asymmetrical, with the maximum of intermediacy displaced towards the area which was being invaded (fig. 9). However, elaborate theoretical analysis would be needed to establish this, and no empirical investigations with this point in mind have yet been made.

Reverting to normal geographical subspeciation, it appears that in spite of the possibility of changes of area, there may exist favoured regions for the intergrading zones between subspecies. This is well brought out, for instance, 
in the maps in Grinnell's paper (1928) on the distribution of birds in Lower California. One such favoured "joint" between subspecies occurs just north of the expansion of the Lower Californian peninsula, from $28^{\circ}$ to $291 / 2 \mathrm{~N}$. lat., the exact locality varying slightly from species to species. In a tuinority of cases, however, no subspecific boundary occurs in this region. A similar tendency occurs in the birds of Nevada (Linsdale, I938). Reinig (1937, p. 4) mentions other regions of subspecific "jointing", in Central Europe, Eastern Siberia, and the Mississippi basin. "These favoured regions for subspecific boundaries are what we prophesied on theoretical grounds. It will be of extreme interest for research to establish (I) the degree to which they do occur in nature; (2) when so, whether they occur, as prophesied, either in regions of rapid environmental change or in those of relative population-sparseness. A peculiar case in squirrels has been déscribed by TномаS and Wroughton (1916). Two distinct species of Callosciurus are separated by the Chindwin river in Burma, but differentiation appears to have been greater on the E. than on the W. bank, for in the same distance of 250 miles, C. sladeni on the east shows 7 subspecies, while C. erythraeus on the west shows only 4. It is, however, possible that continuous clines rather than partially discontinuous subspecies would best fit this case.

In any event it seems clear that the principle of stablilized gene-complexes adapted to regional conditions has been of great importance in evolution, and that it will account for the development of what we may call partial biological discontinuities within a continuous population: It is further clear that this principle of partial discontinuity is itself important in minor systematics, and will result in subspeciation with interbreeding zones whereever areas with sufficient biological tension are involved.

It remains to discuss the application of the cline-concept to these facts and ideas. Theoretically we may assume that selection begins by tending to establish continuous internal clines through any large continuous population. Biological tension, however, introduces partial discontinuities. Where these occur (the intergrading zones) the cline becomes very steep. It may be styled a genocline, since its slope depends solely on the genetic differences between its two ends, and it is not adaptively correlated with any environmental gradation in the narrow zone over which it exists.

Over the remaining areas the cline will clearly be much flattened. What we do not yet know is whether, it will normally or frequently persist with any slope at all, or whether the principle of stabilized gene-complexes will abolish it and introduce regional uniformity within the subspecific areas. The Peromyscus case previously analysed cannot be regarded as typical, first because adaptation is to background which is uniform over large areas, secondly because migration appears to have occurred after differentiation.

In general it may be suggested that the internal clines will not be wholly flattened out. First on account of gene-flow, which will, in spite of selection, 
contaminate at least the margins of the subspecific areas. And more importantly on account of the establishment of internal clines which, so long as they are not too large, can be harmoniously related to the general stabilized genecomplex of the region: such clines will of course only be established if environmental conditions vory considerably within any subspecific area.

If so, then the normal cline condition for continuously inhabited large areas will be that of a stepped ramp, as in II. I. b above (p. 494). However, it is obvious that only laborious research can establish the point.

Partial or total incontinuities will also of course be introduced into regular clines by partial or total isolation, whether geographical or ecological (whereas genetic isolation will, per se, not have the same effect). When the discontinuities are complete, we shall obtain conditions as in I. I (p. 493). Here again, we may expect that where the separate areas are large enough, they will show internal clines, but that these, owing to the barriers to gene-flow introduced by isolation, will be much less steep than the inter-group cline. When the areas are small and uniform, no internal cline will be shown, as in Peromyscus p. leucocephalus. (p. 496).

The existence of isolated small populations intermediate in locality and in character between two other populations, is now a puzzle to some taxonomists. For instances, ENGELS (1936) in describing such a case for an island population of Peromyscus maniculatus, writes, "An insular population, effectively isolated, could not be considered to owe its intermediate character solely to its geographical position, surely not in any appreciable degree to hybridization." While we may agree with him as regards hybridization, the recognition of the existence of clines makes it clear that we should actually expect geographically intermediate populations to be intermediate also in phenotypic character (provided of course, that they also lie on an intermediate position on the environmental gradient with which the cline is correlated). The Fair Isle Wrens, already mentioned, provide a similar case in birds.

The aim of taxonomic names and technical terms in the sphere of minor systematics is to pick out these groups and trends which have a real existence quâ more or -less independent groups in space (see RENsCH, 1934). For this reason, we should rigorously forbid the giving of trinomials to aberrations or to the forms of polymorphic species. The grouping of all white bluebells or white arctic foxes or unbanded Cepea shells together under one subspecific name would actually tend to obscure their relations to the other forms of the species as observed in nature: they do not constitute a real taxonomic unit.

Again, purely ecological forms should not be given subspecific rank unless normally isolated and well differentiated. Otherwise they can be better specified by clines, when the confusion of having subspecific names for continuouslygraded ecological forms as well as relatively discontinuous geographical forms is obviated.

Most genetically-based groups of lower rank than the species can be 
specified either by adding the chromosomal composition in brackets (e.g. $3 \mathrm{n}$, $4 \mathrm{n}, 2 \mathrm{n}+\mathrm{I}, 4 \mathrm{n}-2$ ), or under a special head, e.g. apomicts in forms like Taraxacum.

Meanwhile the thoroughgoing use of the geographical criterion in taxonomy has made it desirable to stabilize the nomenclature of the units of minor systematics. Rensch (1933, 1934) has attempted this, but some of the terms that he proposes (e.g. "genus geographicum" for a group of species that replace eath other geographically) seem unsatisfactory. Other authors would prefer to introduce wholly other terms such as Linneon: however, the term species, with derivatives such as subspecies, is so firmly ingrained that it would be very difficult to ask for its abandonment unless absolutely necessary. The following terminology will probably prove satisfactory for the specification of most (though assuredly not all) taxonomic units and group-trends below the genus or subgenus, i.e. with real existence in nature. Paleontological data appear to demand separate treatment in various respects.

$\begin{array}{ll}\text { Unit } & \text { possible trends within } \\ \text { the unit }\end{array}$

species- Rensch's Artenkreis or genus geogragroup phicum. A collection of related species inter-group (interwhich replace each other geographically and must have arisen by geographical differentiation.

supra- a collection of groups which replace each inter-group clines species other geographically (or physiologically) and in which differentiation has gone so far that the extreme units of the group actually fail to interbreed, or would be classified as separate species if the intermediate units did not exist.

polytypic 'Rensch's Formenkreis. A collection of species groups which replace each other geograspecific) clines phically (or physiologically) and are clearly of subspecific rank only. In some plants, a collection of apomicts.

monotypic Rensch's Art. A group clearly differspecies entiated from related groups as a separate species, but not differentiated into subinter-group (intersubspecific) clines species.

internal (intra-specific) clines 


\begin{tabular}{ll}
\hline Unit significance of unit & $\begin{array}{l}\text { possible trends within } \\
\text { the unit }\end{array}$ \\
\hline
\end{tabular}

subspecies A group partially or wholly isolated from related groups either geographically or physiologically but either intergrading by internal (intra-subspecific) clines crossing with related groups or not differentiated sufficiently to merit specific rank.

apomict

A slightly differentiated group isolated from similar groups within a polytypic species by absence of sexual reproduction

internal (intra-apomict) clines (not yet described)

Ciines of lower order may of course exist within those of higher order; e.g. intra-subspecific within inter-subspecific, and these again within inter-specific clines.

It may prove to be necessary to introduce an additional term for groups within a species which are isolated by some genetic or chromosomal mechanism, but for which the simple indication of the ploidy will not suffice.

Usually it will be clear whether geographical or physiological (ecological) subspecies are intended. When both types of differentiation coexist within a species (geog.) and (ecol.) can be added after the two subspecific names that will then be necessary.

In all cases where graded geographical variation exists, the biologist's ideal aim will of course, be to translate gradients in phenotype into gradients in the percentage of the genes responsible. When the genetic basis for the varying characters is complex, consisting of numerous multiple or modifying factors, as in Peromyscus, this task would be difficult or indeed impossible, even with the fullest genetic data. At the moment, accurate gene mapping could only be achieved where the genetic basis is simple-e.g. in cases of dimorph ratio, and then only when we know which of the two genes is recessive. Analysis of bloodgroups and capacity to taste certain chemical substances in man, however, is revealing the existence of graded gene-distribution in our own species, though here matters are complicated and obscured by migration.

Within the sphere of purely phenotypic investigation, the ideal would be to obtain sufficient data to be able to plot a contour map (phenocontour) instead of one or a few sectional gradients, the contours being isophenes or lines of equal development of the character measured. Such a result is shown in fig. 5 .

For the moment, there will usually be more than enough to do in determining one or two clines for a few prominently varying characters for species or groups of species showing the phenomenon. The geographical lines along 
which the clines are traced need not be straight: it may often be possible to select curved lines of maximum phenotypic change running along gradients in environmental factors such as temperature or humidity.

In any case, it seems clear that the taxonomic description of many forms will be incomplete and indeed inadequate, even when subspecific analysis on current lines has been carried to its limit, without further specification in terms of clines. With the Cole Tits above mentioned, the specification of a cline for increasing yellowness of pale parts from east to west tells us in many ways more about the geographical variation of the species in this area than does the assignment of separate names to the geographically isolated groups, and renders available in handy form a mass of data which otherwise must be dug out from the separate descriptions of the various subspecies.

Coming down to practical considerations, the first step in specification by clines can be of a general and qualitative nature. For instance, one might conclude the description of a species thus: "Species A. b. Constant in south-east of range. North-west of such-and-such a line, showing clines: - (I) increased eumelanin pigmentation, (2) decreased absolute size, (3) increased relative size of extremities, North-South; (4) increased phaeomelanin pigmentation, West-North-West to East-South-East."

The next stage would be the collection of data sufficient to determine statistically significant means at numerous points along selected lines, thus enabling us to plot actual curves for lines specified on a map, as accomplished by Sumner for his deer-mice. In addition, the plotting of coefficients of variability will, as shown above (p. 497) throw light on the question whether continuous population should be divided into named subspecies or not. And finally we may envisage the plotting of isophenes on a phenocontour.

By this means, taxonomy will have at its disposal a new and economical descriptive tool: and further, the data thus amassed will undoubtedly shed light on problems of the differentiation of subspecies, their range-changes subsequent to differentiation, selection-pressure, the rate of spread of genes, and many other questions of general biological interest. 


\section{SUMMARY}

I. The term cline is proposed as an auxiliary taxonomic term, to denote graded spatial variation within a population.

2. This is in no way intended to replace the current methods of taxonomic specification by named areal groups. It may, however, supplement them usefully (a) by stressing continuity as against discontinuity, (b) by effecting synthesis in relating the characters of separate groups to general trends, (c) by obviating the need for assigning names to groups which are only slightly distinot.

3. Clines may be of two rather distinct types: a) compound or inter-group clines, connecting the means of characters of distinct groups (subspecies of a polytypic species, species of an Artenkreis). (b) internal clines, within a whole interbreeding group or any section of it.

4. Clines may concern size, colour, pattern, physiological resistance, the ratio between two or more distinct varieties, etc.

5. Some clines are adaptively correlated, either directly or indirectly, with corresponding environmental gradients or with other environmental factors such as colour of background. Others appear to be correlated with migration from a centre of distribution, still others with the production and subsequent migration of a mutant with positive selective value. Another type not adaptively correlated with environment is that of intermediacy between two distinct subsubspecific types across an interbreeding zone.

6. This last type of cline may be called a genocline. Other main types are geoclines, over large geographical areas, and ecoclines through a range of ecological habitats.

7. Some clines are related to development, in that the greater development of a character is related to greater intensity of rate-genes which determine it.

8. Quantitative figures for a few size geoclines in birds give changes varying from $0.5^{\circ}$ to $2^{\circ} \mathrm{N}$. lat. per $1 \%$ change in size of part affected.

9. The principle of harmoniously stabilized gene-complexes, deduced by R. A. Fisher and others and empirically established by Timofeeff-Ressovsky, will account for the extension of the range of particular genecombinations beyond the areas for which they were initially selected, and the restriction of intermediates to narrow zones between the ranges of the favoured stabilized combinations.

Io. Owing to this principle, the existence of sufficient environmental diversity between different regions of a population's range will establish partial biological discontinuities, the population being broken up into relatively uniform subspecies covering larger areas and separated by interbreeding zones which are kept narrow by selection. 
II. Even in the event of subsequent range-change, the intergrading zones will remain narrow.

12. The production of partial discontinuities will be facilitated by the existence (a) of regions of relatively rapid environmental change, (b) of regions of relatively low population density (partial isolation).

I3. The tendency to produce a regular internal cline will thus be overridden, and replaced by a stepped cline. It is theoretically probable that the subspecific groups in such'cases will show internal clines of slight slope provided that environmental conditions differ sufficiently across the subspecific range.

14. Geographical and physiological (ecological) isolation will also tend to introduce discontinuities into regular clines. The resultant discontinuous intergroup cline will tend to be steeper than the original continuous internal cline, while the internal clines within the various isolated groups will tend to be less steep.

\section{LITERATURE}

Alpatov, W. W., 1929. Quart. Rev. Biol. 4, I.

Chapman, F. M. \& Griscom, L. 1924. Bull. Amer. Mus. Nat. Hist. 50, 279.

Christy, C., 1929. Proc. Zool. Soc. London (1929) 445.

Crampton, H. E., 1916, 1932. Publ. Carnegie Inst. Wash. No. $228,410$.

Engels, W. L., 1936. Amer. Midl. Nat. Notre Dame 17, 776.

Dice, L. R. \& Blossom, P., 1937. Publ. Carnegie Inst. Wash. No. 485.

Dobzhansky, T., 1933. Amer. Nat. 67, 97.

Fischer-Piette, E., 1935. J. Conchyl. 79, 5.

Fisher, R. A., 1930. Amer. Nat. 64, 385. .

Forn, E. B., 1924. Trans. Ent. Soc. Lond. (1923), 692.

Forv, E. B. and Huxley, J. S., 1929. Arch Entw. Mech. Org. 117, 67.

Goldschmidt, R., 1938. Physiological Genetics. New York.

Gregor, J. W., 1938. New Phytol. 37, 15.

Grinnell, J., 1928. Univ. Calif. Publ. Zool. 32, I.

Harris, W. P., 1937. Misc. Publ. Mus. Zool. Univ. Michigan, 38.

Huxley, J. S., 1932. Problems of Relative Growth. London.

-, 1938. Nature 142, 219.

Ingoldby, C. M., 1937. Proc. Zool. Soc. London (1927), 471.

Linsdale, T., I939. Condor, 40, 173.

Meise, W., 1928. J. f. Ornith. 76, I.

Miller, A. H., 1931. Univ. Calif. Publ. Zool. 38, i I.

Miller, A. H. and McCA Ae, T. T., 1935. Condor, 37, 144.

OKLAND, F., 1937. Zoogeogr. 3, 389.

Pearson, T., 1938. Pap. \& Proc. Roy. Soc. Tasmania (1937), 2 I.

RfiniG, W. F., 1937. Die Holarktis. Jena.

$\longrightarrow$ 1938. Elimination und Selektion. Jena.

RensCh, B., 1929. Das Prinzip geographischer Rassenkreise etc. Berlin.

$\longrightarrow$, 1933. Verh. Deutsch. Zool. Ges. 35, 19.

--, 1934. Kurze-Anweisung für zoologisch-systematische Studien. Leipzig.

, 1936. Arch. Naturgesch. (N.F.) 5, 317.

Salomonsen, F., 1933. J. i. Ornith. 81, 100.

Schmidt, J., 1918. J. Genet. 7, 105.

Southern, H. N., 1939. Proc. Zool. Soc. London (A.) 109 (in press). 
Sumner, F. B. 1929. Proc. Nat. Ac. Sci. 15, 110, 481.

- 1932. Bibl. Genet. 9, I.

Swarth, H. S., I920. Univ. Calif. Publ. Zool. $21,75$.

Thomas, O. and Wroughton, R. C., 1916. J. Bombay Nat. Hist. Soc. 24, 224.

Timofeefr-Ressovsky, N. W., 1932. Proc. 6th Internat. Congr, Genet. 2, 230.

- 1935. Arch. Naturgesch. (N.F.) 4, 245.

-, 1939. In "The New Systematics", ed. J. S. Huxley. Oxford.

Vogt, C. and Vogr, O., 1935. Naturwiss. 23, 496.

1938. Sitz und Wesen der Krankheiten. Leipzig.

VoGt, O., 1909. SitzBer. Ges. Naturf. Fr. Berl. (1909), 28.

, I9II. Ibid. (I9II), 31 .

Witherby, H. F. (ed.), rg20-24. A Practical Handbook of British Birds, London.

-, 1938. (ed.) The Handbook of British Birds, London.

WRIGHT, S., 193I. Genetics, 16, 97. 1932. Proc. 6th Internat. Congr. Genet. $1,366$.

Yocum, H. B., \& Huestrs, R. R., 1928. Anat. Rec. 39, 57.

Zimmermann, K., 1935. Arch. Naturgesch. (N.F.) 4, 258. 